\title{
Analisis SWOT dalam Menentukan Strategi Pemasaran Produk Properti PT. Sentra Bumi Nirwana di Sidoarjo
}

\author{
*Bagas Aji Romadhon, Musriha, RM Bramastyo KN \\ Program Studi Manajemen Fakultas Ekonomi dan Bisnis \\ Universitas Bhayangkara Surabaya, Indonesia
}

DOI: $10.46821 /$ benchmark.v2i1.221

\begin{abstract}
Abstrak
Penelitian ini bertujuan untuk mengetahui dan menganalisis strategi pemasaran melalui analisis Strengths, Weaknesses, Opportunities, Threats (SWOT) pada PT. Sentra Bumi Nirwana di Sidoarjo. Peneliti menggunakan pengumpulan data yaitu dengan, observasi, wawancara, dokumentasi, serta kuesioner. Proses bisnis yang berjalan pada PT. Sentra Bumi Nirwana Sidoarjo yaitu membangun perumahan, ruko, gudang, dengan membebaskan lahan terlebih dahulu, kemudian memasarkan ke pembeli secara tunai maupun melalui KPR. Kekuatan yang dimiliki yaitu brand name cukup dikenal masyarakat, kualitas produk yang bermutu, pelayanan yang baik, pengalaman yang relatif panjang, dan konsep perumahan yang baik. Sementara kelemahan yang dimiliki yaitu harga yang kurang menarik, SDM yang kurang berkompeten, kurang pemahaman terhadap pasar, promosi kurang menarik, dan tidak memiliki media website. Peluang yang dimiliki yaitu permintaan properti yang tinggi, petumbuhan pemasok bahan bangunan, dan kebijakan subsidi perumahan. Sedangkan ancaman yang dimiliki yaitu kompetitor yang semakin banyak, pandemi Covid 19, dan daya beli masyarakat menurun. Strategi pemasaran yang paling tepat untuk digunakan yakni strategi agresif atau integrative.
\end{abstract}

Kata Kunci: Strategi pemasaran, Strengths, Weaknesses, Opportunities, Threats.

\begin{abstract}
This study aims to identify and analyze marketing strategies through analysis of Strengths, Weaknesses, Opportunities, Threats (SWOT) at PT. Sentra Bumi Nirwana in Sidoarjo. Researchers used data collection by means of observation, interviews, documentation, and questionnaires. The business process that runs at PT. Sentra Bumi Nirwana Sidoarjo is to build housing, shop houses, warehouses, by acquiring land first, then marketing to buyers in cash or through mortgages. Strengths that are owned are the brand name is well known to the public, quality product quality, good service, relatively long experience, and a good housing concept. Meanwhile, the weaknesses are unattractive prices, incompetent human resources, lack of understanding of the market, less attractive promotions, and no website media. Opportunities that are owned are high demand for property, growth in suppliers of building materials, and housing subsidy policies. Meanwhile, the threats they have are the increasing number of competitors, the Covid-19 pandemic, and the declining purchasing power of the people. The most appropriate marketing strategy to use is an aggressive or integrative strategy.
\end{abstract}

Keywords: Marketing strategy, Strengths, Weaknesses, Opportunities, Threats.

*Corresponding Author:

Hal: $51-59$

Email: bagasajiramadan1997@gmail.com 


\section{PENDAHULUAN}

Suatu perusahaan, khususnya di bidang properti seperti PT. Sentra Bumi Nirwana memerlukan suatu pendekatan dalam memperbaiki kualitasnya dengan memahami karakteristik perusahaan dalam menghadapi segala tantangan dan persaingan dengan melakukan analisis SWOT. Analisis SWOT diartikan sebagai evaluasi terhadap keseluruhan kekuatan, kelemahan, peluang, dan ancaman. Analisis SWOT merupakan alat untuk mengidentifikasi kekuatan dan kelemahan perusahaan serta peluang dan ancaman yang ada. Faktor kekuatan dan kelemahan merupakan faktor yang disebabkan oleh internal perusahaan, sedangkan peluang dan ancaman merupakan faktor yamg disebabkan oleh pihak eksternal perusahaan atau lingkungan eksternal (Kotler \& Keller, 2016:63).

Melalui analisis SWOT ini perusahaan diharapkan mampu memahami semua kekuatan dan kelemahan serta peluang dan ancaman perusahaan. Dengan demikian perusahaan dapat menyusun strategi yang tepat dalam rangka menghadapi persaingan di pasar. Selain itu, melalui analisis SWOT perusahaan dapat mengantisipasi segala perubahan di pasar bisnis yang disebabkan oleh perkembangan teknologi di segala bidang. Salah satu cara untuk mencapai tujuan perusahaan adalah dengan mengetahui apa kebutuhan dan keinginan konsumen atau pasar sasaran serta memberikan kepuasan yang diharapkan secara lebih efektif dan efisien dibandingkan para pesaing.(Istanti, 2019:17).

Penelitian yang dilakukan oleh Galib (2017) menunjukkan bahwa Hasil analisis strategi pemasaran dengan metode analisis SWOT, nampak bahwa PT. IBB yang merupakan perusahaan properti mempunyai peluang pasar yang besar. Meskipun demikian perusahaan ini menghadapi kelemahan internal. Dalam kondisi seperti ini perusahaan sebaiknya menggunakan strategi pengembangan pasar turnaround yaitu meminimalkan masalah masalah internal perusahaan sehingga dapat merebut pasar. Dari I-E Matriks nampak bahwa PT. IBB berada pada sel growth and build. Hal ini berarti strategi yang sebaiknya dilakukan perusahaan adalah stategi intensif seperti pengembangan pasar, penetrasi pasar dan pengembangan produk perumahan. Sementara itu penelitian yang dilakukan oleh Apriliani (2019) menunjukkan bahwa posisi strategi promosi Perumahan Green Serpong Bintaro berada pada kondisi prospektif (kuadran I) dari Matrik Kondisi. Hal ini menunjukan bahwa perusahaan berada pada kondisi yang baik untuk menggunakan kekuatan internalnya guna memanfaatkan peluang eksternal, mengatasi kelamahan internal, dan menghindari ancaman eksternal. Posisi perusahaan berada pada kuadran I (prospektif) yang berarti strategi yang dijalankan adalah dengan menggunakan strategi S-O (Strength-Opportunity) yaitu: Menjalin hubungan baik dengan marketing KPR dan vendor/Supllier, Mengoptimalkan program pemasran secara langsung atau tidak langsung, Memaksimalkan promosi kepada captive market, Banyak mencari informasi mengenai bunga KPR dari Bank yang berbeda, Menjaga kelestarian lingkungan dan fasilitas perumahan. Kedua penelitian tersebut menghasilkan temuan yang berbeda, sehingga perlu dilakukan kajian ulang.

Berkaitan dengan hal tersebut maka peneliti tertarik untuk melakukan penelitian tentang Analisis SWOT dalam menentukan strategi pemasaran produk properti PT Sentra Bumi Nirwana di Sidoarjo. Tujuan penelitian ini adalah untuk mengetahui dan menganalisis strategi pemasaran melalui analisis Strengths, Weaknesses, Opportunities, Threats (SWOT) pada PT Sentra Bumi Nirwana di Sidoarjo. 


\section{TINJAUAN PUSTAKA}

\section{Strategi Pemasaran}

Strategi pemasaran ialah rencana yang menyeluruh, terpadu dan menyatu dibidang pemasaran, yang memberikan panduan tentang kegiatan yang akan dijalankan untuk dapat tercapainya tujuan pemasaran suatu perusahaan (Tjiptono, 2015:5). Adapun langkah-langkah strategi pemasaran antara lain memutuskan proposisi nilai, mendiferensiasikan penawaran pasar untuk menciptakan nilai pelanggan yang unggul, positioning memposisikan penawaran pasar dalam fikiran pelanggan pasar, menciptakan nilai bagi pelanggan sasaran, memilih pelanggan yang dilayani, segmen membagi seluruh pasar menjadi segmen yang lebih kecil, dan penetapan sasaran memilih satu atau beberapa segmen yang dimasukkan.

\section{Analisis Strengths, Weaknesses, Opportunities, and Threats (SWOT)}

Menurut Rangkuti (2015:18) menyatakan bahwa analisis SWOT merupakan upaya untuk mengidentifikasi beberapa faktor secara sistematis dalam rangka untuk membuat rumusan strategi perusahaan. Analisis SWOT didasarkan pada logika yang mampu menghasilkan adanya kekuatan (strengths) dan kesempatan (opportunities) tetapi secara simultan mampu meminimalkan kelemahan (weaknesses) yang terdapat pada organisasi dan ancaman (treaths) yang dialami oleh organisasi. Analisis SWOT dalam rangka mengetahui strengths, weaknesses, opportunities, dan treaths."

\section{Hasil Penelitian Terdahulu}

Penelitian Srinadi (2016) menyatakan bahwa analisis SWOT Sebagai Dasar Menentukan Strategi Pemasaran Kompetitif' (Studi Kasus: Usaha Jasa Dekorasi X), hasil dari penelitian ini adalah organisasi berada pada kuadran SO (Strenght - Opportunity) di mana perusahaan terus berjalan dengan memanfaatkan kekuatan dan peluang yang ada pada Perusahaan tersebut. Sementara penelitian Afrilita (2013), Analisis SWOT dalam Menentukan Strategi Pemasaran Sepeda Motor Pada PT. Samekarindo Indah di Samarinda, PT. Samekarindo Indah dapat menggunakan alternatif strategi-strategi berikut, di antaranya strategi Strengths - Opportunities, antara lain (a) pertahankan dan tingkatkan kualitas produk maupun pelayanan purna jual, (b) pengembangan pasar menengah kebawah, dan (c) mengadakan kegiatan eksibisi. Kemudian strategi Weaknesses - Opportunities, antara lain, (a) promosi yang terarah, (b) promosi yang lebih gencar dengan mengadakan, mengikuti atau sebagai sponsor di berbagai event, promosi melalui media cetak dan media jejaring sosial, dan (c) menambah sub dealer. Sedangkan untuk strategi Strenghts - Threats, di antaranya (a) mengembangkan daya saing, dan (b) meningkatkan hubungan baik dengan pelanggan. Sementara itu, strategi Weaknesses Threats, di antaranya (a) memperluas area promosi dengan membuka outlet -outlet untuk memperluas jaringan penjualan, (b) menambah variasi penjualan dealer seperti menjual aksesoris motor yang sedang trend di masyarakat, dan (c) memberikan diskon harga spare partbagi konsumen yang loyal. Astuti \& Ratnawati (2020) dengan judul "Analisis SWOT dalam Menentukan Strategi Pemasaran (Studi Kasus di Kantor Pos magelang 56100)", total skor dari faktor kekuatan, kelemahan, peluang dan ancaman, masing masing diperoleh bobot kekuatan tertinggi 0,55, bobot kelemahan tertinggi 0,40 , bobot peluang tertinggi 0,55 , dan bobot ancaman. 
METODE PENELITIAN

Lokasi dan waktu penelitian

Penelitian ini dilaksanakan di PT. Sentra Bumi Nirwana Sidoarjo.

\section{Pendekatan penelitian}

Pendekatan penelitian dilakukan dengan pendekatan kualitatif.

\section{Metode Pengumpulan Data}

Pengumpulan data menggunakan metode wawancara, observasi, dokumentasi, dan kuesioner.

Analisis Data

Data penelitian ini dianalisis dengan beberapa tahap, yakni matriks SWOT, matriks IFAS, matriks EFAS, dan matriks Internal dan Eksternal (IE).

\section{HASIL ANALISIS DAN PEMBAHASAN}

Tabel 1 menunjukkan bahwa strategi pemasaran PT. Sentra Bumi Nirwana Menggunakan Analisis Strength, Weakness, Opportunity, and Threat (SWOT).

Komponen yang paling mendominasi untuk faktor internal antara kekuatan atau kelemahan pada perusahaan PT. Sentra Bumi Nirwana adalah kekuatan yaitu sebesar 2,23 sedangkan untuk kelemahannya sebesar 1,86. Adapun yang paling tinggi bobot skor factor kekuatan adalah kualitas produk dan pengalaman dalam bisnis properti. Sementara kelemahan tertingginya ada pada aspek harga yang kurang menarik (Tabel 2).

Komponen yang paling mendominasi untuk faktor eksternal antara peluang atau ancaman pada PT Sentra Bumi Nirwana dalam pemasarannya adalah peluang yang dapat dilihat pada Tabel 3.

Untuk menetukan pilihan strategi yang lebih spesifik dari nilai yang didapat dimasukkan ke dalam diagram pilihan strategi, karena hasil dari tabel 4 terlihat bahwa dari skor yang ada mengarah pada pilihan agresif (growth) selanjutnya menentukan agresif strategy yang lebih spesifik.

Berdasarkan skor yang menunjukkan bahwa kekuatan (Strengths) lebih besar dari kelemahan (Weaknesse), sehingga hasilnya nampak pada Gambar 1.

Tabel 1

\section{Matrik SWOT}

\begin{tabular}{ll}
\hline Strengths & Weakness \\
a. Brand name cukup kuat & a. Harga yang kurang menarik \\
b. Kualitas produk yang bermutu & b. SDM yang kurang berkompeten \\
c. Pelayanan yang baik & c. Kurang pemahaman terhadap pasar \\
d. Pengalaman yang relatif panjang & d. Promosi yang kurang menarik \\
e. Konsep perumahan yang baik & e. Tidak memiliki media website \\
\hline Opportunity & Threats \\
a. Permintaan property yang tinggi & a. Kompetitor semakin banyak \\
b. Pertumbuhan pemasok & b. Pandemi Covid-19 \\
c. Kebijakan subsidi pemerintah & c. Daya beli masyarakat turun \\
\hline
\end{tabular}

Sumber: Peneliti (2021) 


\section{Tabel 2}

Internal Factor Evaluation (IFE)

\begin{tabular}{lccc}
\hline \multicolumn{1}{c}{ Faktor Strategis Internal } & Bobot & Rating & Bobot Skor \\
\hline Kekuatan & & & \\
1. Brand name cukup kuat & 0,10 & 4,5 & 0,43 \\
2. Kualitas produk & 0,11 & 4,5 & 0,49 \\
3. Pelayanan yang baik & 0,10 & 4,5 & 0,43 \\
4. Pengalaman yang relatif panjang & 0,12 & 4 & 0,49 \\
5. Konsep perumahan & 0,11 & 3,5 & 0,38 \\
Sub Total & 0,53 & 21,00 & 2,23 \\
Kelemahan & & & \\
1. Harga yang kurang menarik & 0,10 & 4,5 & 0,43 \\
2. SDM yang kurang berkompeten & 0,08 & 4 & 0,33 \\
3. Kurang pemahaman terhadap & 0,10 & 4 & 0,38 \\
$\quad$ konsumen & 0,10 & 4 & 0,38 \\
4. Promosi kurang menarik & 0,10 & 3,5 & 0,34 \\
5. Tidak memiliki media website & 0,47 & 20,00 & 1,86 \\
Sub Total & 1,00 & 41,00 & 4,10 \\
Total
\end{tabular}

Sumber: Peneliti (2021)

Tabel 3

External Factor Evaluation (EFE)

\begin{tabular}{|c|c|c|c|c|}
\hline No & Faktor Ekternal & Bobot & Rating & Bobot Skor \\
\hline \multicolumn{5}{|c|}{ Peluang } \\
\hline 1. & Permintaan properti yang tinggi & 0,19 & 3,8 & 0,71 \\
\hline 2 . & Pertumbuhan pemasok & 0,16 & 4 & 0,65 \\
\hline 3. & Kebijakan subsidi pemerintah & 0,16 & 3,4 & 0,55 \\
\hline Sub ? & otal & 0,51 & 11,20 & 1,91 \\
\hline \multicolumn{5}{|c|}{ Ancaman } \\
\hline 1. & Kompetitor semakin banyak & 0,16 & 2,6 & 0,42 \\
\hline 2. & Pandemi Covid & 0,16 & 2,4 & 0,39 \\
\hline 3. & Daya beli masyarakat turun & 0,16 & 2,8 & 0,46 \\
\hline Sub & otal & 0,49 & 7,80 & 1,27 \\
\hline Total & & 1,00 & 19,00 & 3,18 \\
\hline
\end{tabular}

Sumber: Peneliti (2021)

Tabel 4

Rekapitulasi Skor IFE dan EFE

\begin{tabular}{ccl}
\hline Skor Internal & Skor Eksternal & \multicolumn{1}{c}{ Pilihan Strategi } \\
\hline $\mathrm{S}>\mathrm{W}(+)$ & $\mathrm{O}>\mathrm{T}(+)$ & Agresif $($ Growth $)$ \\
$2,23>1,86$ & $1,91>1,21$ & \\
$\mathrm{~S}<\mathrm{W}(-)$ & $\mathrm{O}<\mathrm{T}(-)$ & Survival \\
$\mathrm{S}>\mathrm{W}(+)$ & $\mathrm{O}<\mathrm{T}(-)$ & Diversification \\
$\mathrm{S}<\mathrm{W}(-)$ & $\mathrm{O}>\mathrm{T}(+)$ & Stability \\
\hline
\end{tabular}

Sumber: Peneliti (2021) 


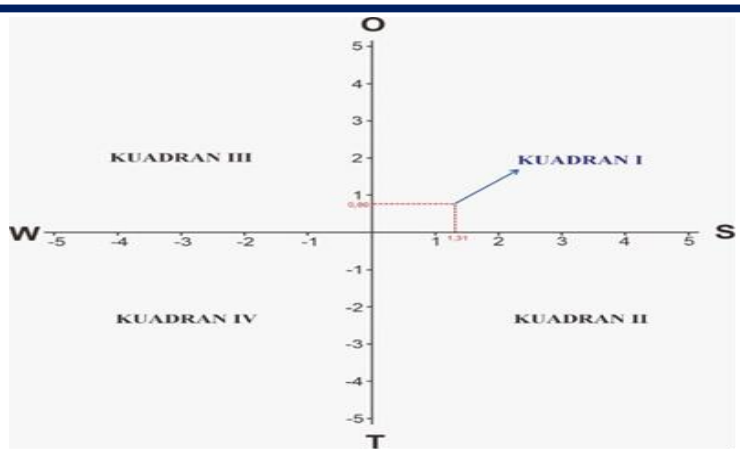

Gambar 1

Diagram Analisis SWOT

Tabel 5

Hasil Analisis Matriks SWOT

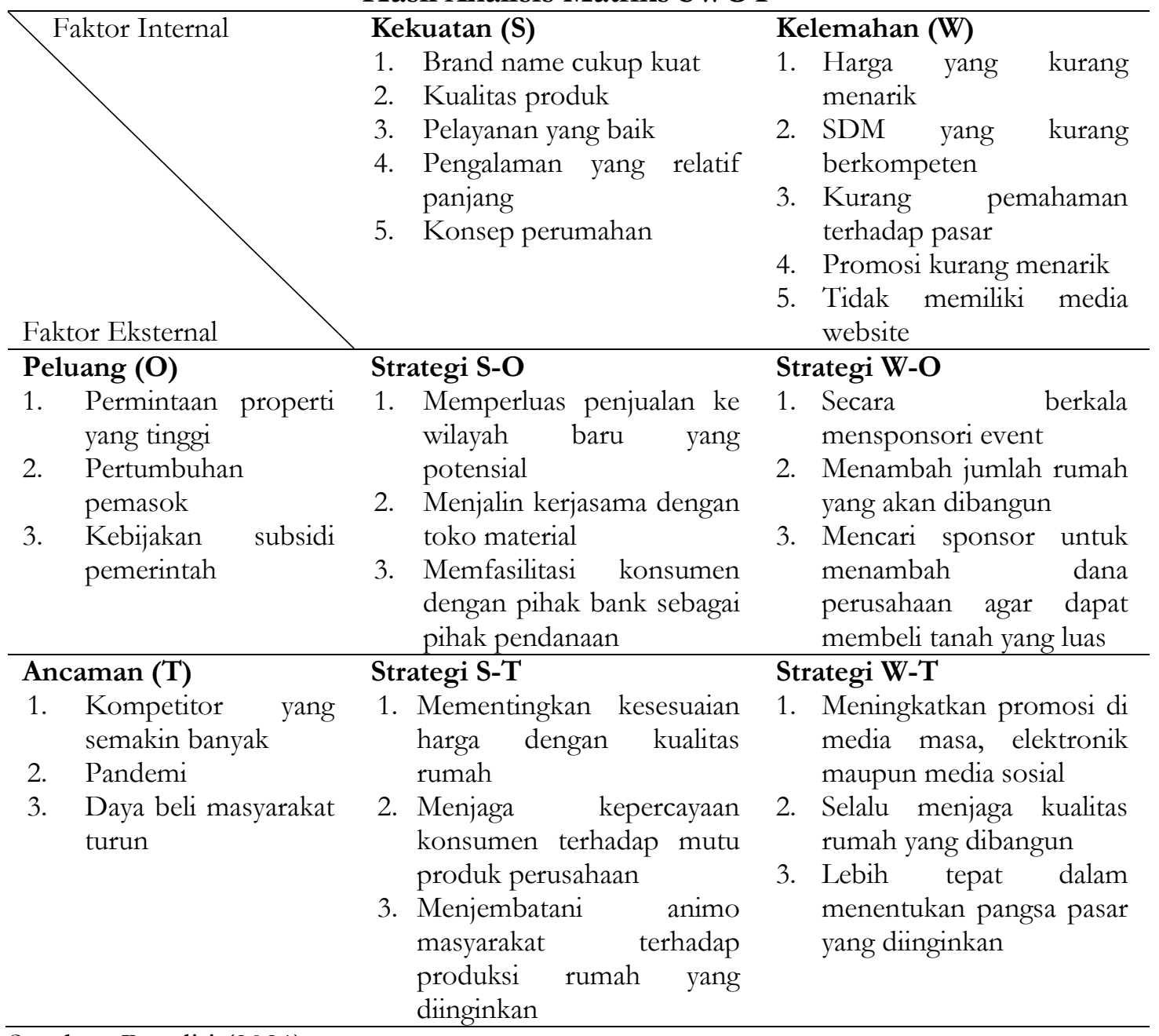

Sumber: Peneliti (2021) 
PT Sentra Bumi Nirwana dalam pemasarannya menempati posisi dalam kuadran I. Hal ini menunjukkan bahwa perusahaan berada pada posisi Strategi Agresif. Strategi yang tepat digunakan pada kuadran ini adalah strategi agresif (penetrasi pasar, pengembangan pasar) atau integrative (integrasi kebelakang, integrasi kedepan dan integrasi horizontal). Strategi yang dapat dilakukan berdasarkan lingkungan internal dan eksternal perusahaan, berupa strategi penetrasi pasar dan pengembangan produk. Strategi penetrasi pasar adalah mencari pangsa pasar yang lebih besar untuk produk dan jasa yang sudah ada sekarang melalui usaha pemasaran yang lebih gencar. Penetrasi pasar meliputi penambahan kapasitas produk, jumlah tenaga penjualan (saluran distribusi), peningkatan pengeluaran untuk iklan, penawaran produk-produk dan promosi penjualan secara intensif. Dengan kata lain strategi ini dapat dilakukan dengan melakukan promosi yang lebih gencar.

Pengembangan produk adalah sebuah strategi yang mengupayakan peningkatan penjualan dengan cara memperbaiki atau memodifikasi produk atau yang ada saat ini. Strategi ini dapat dilakukan dengan meningkatkan kualitas produk yang dihasilkan oleh PT Sentra Bumi Nirwana. Produk juga dapat dikembangkan dengan menambah jumlah varian produk atau tipe perumahan, selain untuk memperbanyak pilihan bagi konsumen penambahan varian produk juga untuk mempertahankan konsumen agar tetap membeli produk perumahan dengan variasi yang berbeda dengan kualitas yang sama baiknya sesuai dengan kebutuhan masing-masing konsumen.

\section{Rekomendasi Pengembangan Strategi Pemasaran PT. Sentra Bumi Nirwana}

Berdasarkan uraian tentang Formulasi strategi yang dilakukan dengan menggunakan analisis SWOT, maka dapat dibuat Matriks SWOT yang dapat dilihat pada Tabel 5.

\section{SIMPULAN DAN SARAN}

Berdasarkan hasil penelitian dapat disimpulkan bahwa proses bisnis yang berjalan pada PT. Sentra Bumi Nirwana Sidoarjo yaitu membangun perumahan, ruko, gudang, dengan membebaskan lahan terlebih dahulu, kemudian memasarkan ke pembeli secara tunai maupun melalui KPR. Kekuatan yang dimiliki PT. Sentra Bumi Nirwana Sidoarjo yaitu brand name cukup dikenal masyarakat, kualitas produk yang bermutu, pelayanan yang baik, pengalaman yang relatif panjang, dan konsep perumahan yang baik. Sementara kelemahan yang dimiliki PT. Sentra Bumi Nirwana Sidoarjo yaitu harga yang kurang menarik, SDM yang kurang berkompeten, kurang pemahaman terhadap pasar, promosi kurang menarik, dan tidak memiliki media website. Peluang yang dimiliki PT. Sentra Bumi Nirwana di Sidoarjo yaitu permintaan properti yang tinggi, petumbuhan pemasok bahan bangunan, dan kebijakan subsidi perumahan. Sedangkan ancaman yang dimiliki PT. Sentra Bumi Nirwana di Sidoarjo yaitu kompetitor yang semakin banyak, pandemi Covid 19, dan daya beli masyarakat menurun. Strategi pemasaran yang paling tepat untuk digunakan oleh PT. Sentra Bumi Nirwana di Sidoarjo berdasarkan posisi kuadran I yang merupakan posisi Grow and Build (tumbuh dan berkembang) adalah strategi agresif (penetrasi pasar, pengembangan pasar, pengembangan produk) atau integrative (integrasi kebelakang, integrasi kedepan dan integrasi horizontal). Rekomendasi terhadap strategi pemasaran PT. Sentra Bumi Nirwana adalah sebagai berikut: Strategi SO (StrengthOpportunity), yakni memperluas penjualan ke wilayah baru yang potensial, mejalin kerjasama dengan toko material, memfasilitasi konsumen dengan pihak bank sebagai 
pihak pendanaan, agar terjaga kepuasan dan loyalitasnya. Strategi ST (Strength-Threat), yakni mementingkan kesesuaian harga dengan kualitas rumah, menjaga kepercayaan konsumen terhadap mutu produk perusahaan, menjembatani animo masyarakat terhadap produksi rumah yang diinginkan, agar tercipta kepuasan pelanggan. Strategi WO (Weakness-Opportunity), yakni secara berkala mensponsori event, dalam rangka mengenalkan perusahaan dan produk perumahanya, menambah jumlah rumah yang akan dibangun, agar mampu memenuhi kebutuhan dan keingginan konsumen, dan encari sponsor untuk menambah dana perusahaan agar dapat membeli tanah yang luas. Strategi WT (Weakness-Threat), yakni meningkatkan promosi di media massa, elektronik, maupun media sosial, agar mampu mendorong penjualan produk, selalu menjaga kualitas rumah yang dibangun dalam rangka meningkatkan kepuasan pelanggan, lebih tepat dalam menentukan pangsa pasar yang diinginkan.

\section{DAFTAR PUSTAKA}

Achmad Daengs, G. S., Istanti, E., Bramastyo Kusuma Negoro, R. M., \& Sanusi, R. (2020). The aftermath of management actions on competitive advantage through process attributes at food and beverage industries export import in Perak Harbor of Surabaya. International Journal of Criminology and Sociology, 9, 1418-1425. https://doi.org/10.6000/1929-4409.2020.09.162.

Achmad Daengs GS1, Enny Istanti2, M. Y. R. P. (2021). Challenges of Exchange Rate Fluctuation and Cpo Prices in Indonesia Palm Oil Industry. IJEBD, 04(03), 356362. https://doi.org/https://doi.org/10.29138/ijebd.v4i3.1379.

Afrilita, N. (2013). Analisis SWOT dalam Menentukan Strategi Pemasaran Sepeda Motor pada PT. Samekarindo Indah di Samarinda. Journal Adminsitrasi Bisnis, 1 (1).

Apriliani, S. (2019). Analisis Startegi Promosi Untuk Meningkatkan Penjualan Perumahan Green Serpong Bintaro. Jurnal Pemasaran Kompetitif, 3 (1), 69. https://doi.org/10.32493/jpkpk.v3i1.3619.

Astuti, A. M. I., \& Ratnawati, S. (2020). Analisis SWOT dalam Menentukan Strategi Pemasaran (Studi Kasus di Kantor Pos Kota Magelang 56100). Jurnal Ilmu Manajemen, 17(1), 58-70.

Daengs GS, A., Kurniasih, N., Reni, A., Istanti, E., Zuhroh, D., \& Qomariah, N. (2019). The Effect of Business Sphere on Competitive Advantage and Business Performance of SMEs. Management Science Letters, 9(8), 1153-1160. https://doi.org/10.5267/j.msl.2019.4.025.

Enny Istanti1), Bramastyo Kusumo2), I. N. (2020). Implementasi Harga, Kualitas Pelayanan dan Pembelian Berulang pada Penjualan Produk Gamis AfiFATHIN. Ekonomika 45, 8(1), 1-10. 
Galib, M. (2017). Analisis Strategi Pemasaran Perumahan di Makassar (Studi Kasus PT Indah Bumi Bosowa). AkMen: Jurnal Ilmiah, 14(1), 171-184.

Istanti, E. (2019). Pengaruh Harga, Promosi dan Produk terhadap Keputusan Pembelian di Restoran Burger King Kawasan Surabaya Plaza Surabaya. Ekonomika’45, 7(1), 16-22. https://doi.org/.1037//0033-2909.I26.1.78

Istanti, E., Kn, R. M. B., \& Gs, A. D. (2021). Efforts to Empower MSMEs in Panci Village in Increasing Family Income (Study on MSMEs in Panci Village in Porong District, Sidoarja Regency ). 2021(2), 497-504.

Kotler, P., \& Keller, K. L. (2016). Marketing Mangement. In Pearson Edition Limited.

Rangkuti, F. (2015). Teknik Membedah Kasus Bisinis Analisis SWOT. In PT. Gramedia Pustaka Utama.

Srinadi, N. L. P. (2016). Analisis SWOT Sebagai Dasar Menentukan Strategi Pemasaran Kompetitif (Studi Kasus: Usaha Jasa Dekorasi X). Seminar Nasional Teknologi Informasi dan Komunikasi 2016 (SENTIKA 2016), 2016(Sentika).

Tjiptono, F. (2015). Strategi Pemasaran. (Edisi 4:). Andi. 